\title{
Informational-Statistical Aspects of Genetic Diversity in Tsigai and Tsurcana Ecotypes from Romania
}

\author{
Gheorghe HRINC $\breve{A}^{1}$ \\ ${ }^{1}$ Research and Development Station for Sheep and Goat Breeding, Popauti-Botosani, 717310, Romania \\ ${ }^{*}$ Corresponding author, e-mail: ghrinca@yahoo.com
}

Bulletin UASVM Animal Science and Biotechnologies 74(2)/ 2017

Print ISSN 1843-5262; Electronic ISSN 1843-536X

DOI:10.15835/buasvmcn-asb: 0014

\begin{abstract}
The main objective of this paper is to measure the relationships between the ecotypes belonging to the Tigai and Tsurcana breeds of Romania and to quantify the genetic diversity within them from the informational statistics point of view, depending on the relief forms of the biotope in which they live, using the genetic variants of some selective genetic markers. The researches were carried out on ecotypes of the most ubiquitous sheep breeds in Romania, Tsigai and Tsurcana whose biotopes are circumscribed by more relief forms: plain, hilly, sub-mountainous and mountainous. The sheep were electrophoretically typified at the determinant loci of haemoglobin and transferrin. Using the allelic frequencies of the haemoglobin and transferrin systems that have been processed by concepts of informational statistics, the differentiation / similarity degree among ecotypes within the two breeds was quantified by the genetic distance $(\boldsymbol{D})$ and the informational correlation coefficient $\left(\boldsymbol{R}_{x, y}\right)$, as well as the diversity level $(\boldsymbol{d})$ of the genetic structures of these ecotypes on the basis of informational energy $(\boldsymbol{e})$. Also, the heterozygosity degree $(\boldsymbol{H t})$ at the $\mathrm{Hb}$ and $\mathrm{Tf}$ loci was calculated in relation to the genetic diversity level. The paper analyzes the causes of genetic similarities and differentiations among the ecotypes of these two breeds at the level of the two biochemicalgenetic loci: allelic distribution of haemoglobin and transferrin, altitude of relief forms, habitat conditions etc. The benefits of such studies are also presented for the improvement, breeding and conservation of the ecotypes of these two sheep breeds from Romania.
\end{abstract}

Keywords: ecotype, genetic distance, informational correlation, genetic diversity, sheep.

\section{INTRODUCTION}

The breed as a biological taxonomic entity is specific to the domestic animal breeding domain with an overwhelming contribution of empirical or systematic artificial selection exercised by man to improve the productivity potential of animals. The breed creating is a historical, complex and extremely laborious process, sometimes of very long lasting. Once the breed formed, it is presented as a population or group of populations within a species characterized by common morphological, biochemical, physiological, genetic, productivity and ecological features, all being hereditarily fixed. For this reason, the breed is assimilated to subspecies. Having shaped this profile, a breed differs from other breeds, precisely through this complex of attributes (Grosu and Drăgănescu, 2003).

The breed created occupies a limited area in which it lives, being adapted to the environmental conditions of the respective biotope. But during its evolution, this area can be expanded or, by migration phenomena in closer or more remote areas, the animals of the same breed adapt to new environmental conditions, conquering areas whose meteorological, geographic and climatic characteristics are different from the original ones in which the breed was created (Scher et al., 2012). Through this process, theecotypes (biotypes) occur, representing individual groups of the same breed 
with their own hereditary properties acquired under the influence of environmental conditions, mostly by natural selection, adapted to the new habitat. The differentiation process of ecotypes can be so emphasized that the reproductive isolation is possible, which creates prerequisites for defining these ecotypes as new breeds (Grosu and Drăgănescu, 2003; Paraschivescu et al., 2009; Gáspárdy, 2011).

The specific features of ecotypes are rather genetic and ecological since the environmental conditions exert selective pressure on the genetic material (Zanoti Casati et al., 1990; Sargent et al., 1999; Gáspárdy, 2011; Ozdemir et al., 2011). Thus, among these subspecific subdivisions, certain biological relationshiphips are established, resulting more or less significant differentiations, leading to an increase in biodiversity within that breed (Paraschivescu et al., 2009).

For this reason, we decided to quantify the relationships among the ecotypes belonging to the Tsigai and Tsurcana breeds of Romania from the informational statistics point of view, depending on the relief forms of the biotope in which they live, using the genetic variants of some selective genetic markers (haemoglobin and transferrin).

\section{MATERIALS AND METHODS}

Several ovine populations of the Tsigai and Tsurcana breeds were investigated to reveal some aspects of genetic similarity or diversity among them and within them. The size of these samples was according to the area occupied by each of them (Figs. 1, 2, 7, 8). These populations are in fact the main ecotypes of the two Romanian sheep breeds and were sampled according to the relief forms of their existence areas: plain, hill, sub-mountain and mountain. The altitude as an essential element defining the reliefforms is associated with the other environmental conditions in the respective areas: rainfall, luminosity, thermal regime, vegetation for pasture, etc. All these elements outline the complex meteorological, geographic and climatic context in which the ecotypes take their place and influence their productivity standard (to a lesser extent) and their genetic profile (in a wider range).

For the accuracy of the study, we analyzed these two breeds because they are ubiquitous in Romania. Compared to the other two classical Romanian breeds, Palas Merino (spread only in Dobrudja and in the South of our country) and
Botosani Karakul (located in the north-eastern Moldavia), the Tsigai and Tsurcana breeds are spread in several areas of Romania with different weather conditions. In fact, the Palas Merino and Botosani Karakul breeds are not differentiated into ecotypes.

Two biochemical-genetic markers were determined, haemoglobin and transferrin, polymorphic proteins having an essential role in adapting of animal organisms to the environmental conditions and technological factors.

The typifying of individuals at the loci of the two proteins was performed by the horizontal electrophoresis method, having the starch gel as substrate and using the buffer solutions of Tris (hydroxymethyl) aminomethane, EDTA.Na ${ }_{2}$, boric acid, citric acid and lithium hydroxide as electrolyte, the recipes for reagents being formulated depending on the protein analyzed. Electrophoresis lasted four hours for haemoglobin and 6-8 hours for transferin, until the electrophoretic bands migrated to $4 \mathrm{~cm}$, respectively to $11 \mathrm{~cm}$, to the starting line. The power intensity was $40 \mathrm{~mA}$ and $50 \mathrm{~mA}$ and its voltage was $300 \mathrm{~V}$ and $400 \mathrm{~V}$ for haemoglobin, respectively for transferrin. The colouring of starch gels was made with an alcoholic-acid solution of $1 \%$ amidoschwartz 10B, and their discolouring in a solution of methanol, glacial acetic acid and distilled water $(3 / 1 / 3)$. (Hrinca and Vicovan, 2010, 2011).

The degree of genetic differentiation/ similarity was calculated in two ways:

- an estimate through the genetic distance (D) (according to the Nei method), by the expression:

$\mathbf{D}=-\log _{\mathrm{e}} \frac{J x \cdot y}{(J x . J y)^{1 / 2}}=2$ at, where:

- $\mathrm{D}=$ standard genetic distance;

- $\mathrm{t}=$ differentiation time;

- a - substitution percentage of genes per locus and per year, whose value is $10^{-7}$.

- Jxy = probability of genetic identity between two populations $x$ and $y$;

-Jx - probability of genetic identity within the population $x$ :

-Jy - probability of genetic identity within the population $y$ : 


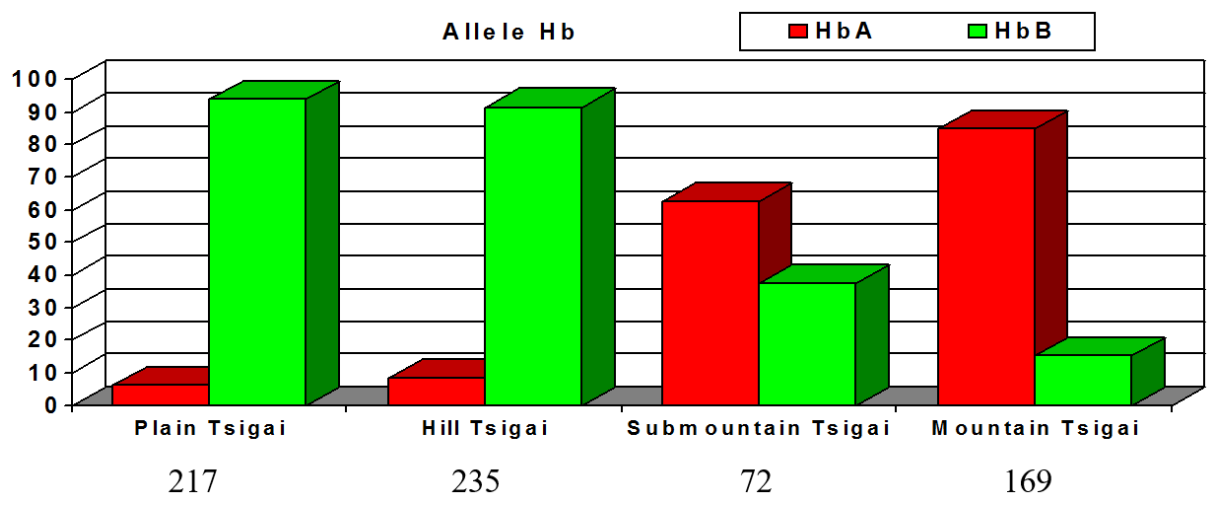

Fig. 1. Allelic structure at the Hb locus in different Tsigai ecotypes

- a more accurate measurement through the informational correlation $\left(\boldsymbol{C}_{x, y}\right)$ (according to the Onicescu-Ștefănescu method), by the formula (Hrinca, 2015):

$\mathbf{R}_{\mathrm{x}, \mathrm{y}}=\frac{\sum_{i=1}^{n} f_{\dot{x}} f_{\dot{y}}}{\sqrt{\left(\sum_{i=1}^{n} f_{\dot{x}}^{2} \gamma \sum_{i=1}^{n} f_{\dot{y}}^{2}\right)}}$ where

$\mathrm{R}_{\mathrm{x}, \mathrm{y}}$ - informational coefficient correlation;

$f_{\dot{x}}$ and $f_{\dot{y}}$ are the frequencies for the population $x$ and $y$.

The level of genetic diversity ( $\boldsymbol{d}$ ) of these two polymorphic systems was quantified by the informational energy (e), according to mathematical monotony:

$\boldsymbol{d}=\mathbf{1}-\boldsymbol{e}$, in which

$\boldsymbol{e}=\frac{\left(\sum_{i=1}^{m} p_{i}^{2}-\frac{1}{m}\right)}{\left(1-\frac{1}{m}\right)}$ where

$\mathrm{p}=$ the probability (which ranges from 0 to 1 );

$\mathrm{m}=$ number of classes (statuses).

In relation to genetic diversity, the heterozygosity degree $(\boldsymbol{H t})$ of ecotypes was evaluated by the following expression (Hrinca, 2015):
$H=\left[\frac{2 n}{2 n-1}\right]\left[1-\sum_{i=1}^{k} x_{i}^{2}\right]$, where:

$\mathrm{Ht}=$ the heterozigosity of population $k$;

$\mathrm{n}=$ the number of individuals;

$\mathrm{x}=$ the allelic frequency at the locus $i$.

\section{RESULTS AND DISCUSSIONS}

The susceptible number of ecotypes taken in the informational statistics analyzes within each genetic-biochemical system depended on their number typified at the two polymorphic loci.

\section{Particularities of biodiversity in the Tsgai ecotypes}

The Tsigai ecotypes that have been used to reveal some aspects of biodiversity are defined according to the relief forms in which they carry their existence: plain Tsigai (Rusetu, Buzau County), hill Tsigai (Secuieni, Bacau county), sub mounting Tsigai (Ciuc Depression, Harghita County) and mountain Tsigai (Calimani-Gurghiu Massif, Mures County).

\subsection{Allelic structures of biochemical-genetic systems}

Allelic structures at the determinant locus of haemoglobin

In the Tsigai breed, the lowest frequency of the $\mathrm{Hb}^{\mathrm{A}}$ allele $(6.04 \%)$ is found in the flocks living on the plain (Rusetu ecotype). Its frequency begins to increase slightly $(8.50 \%)$ in sheep from hill areas (Secuieni ecotype); in both Tsigai ecotypes the $\mathrm{Hb}^{\mathrm{B}}$ allele is very spread (over 90\%). On the plateau and in the sub-mountain regions (Ciuc Depression), the $\mathrm{Hb}^{\mathrm{A}}$ allele is much more frequent $(62.50 \%)$ 


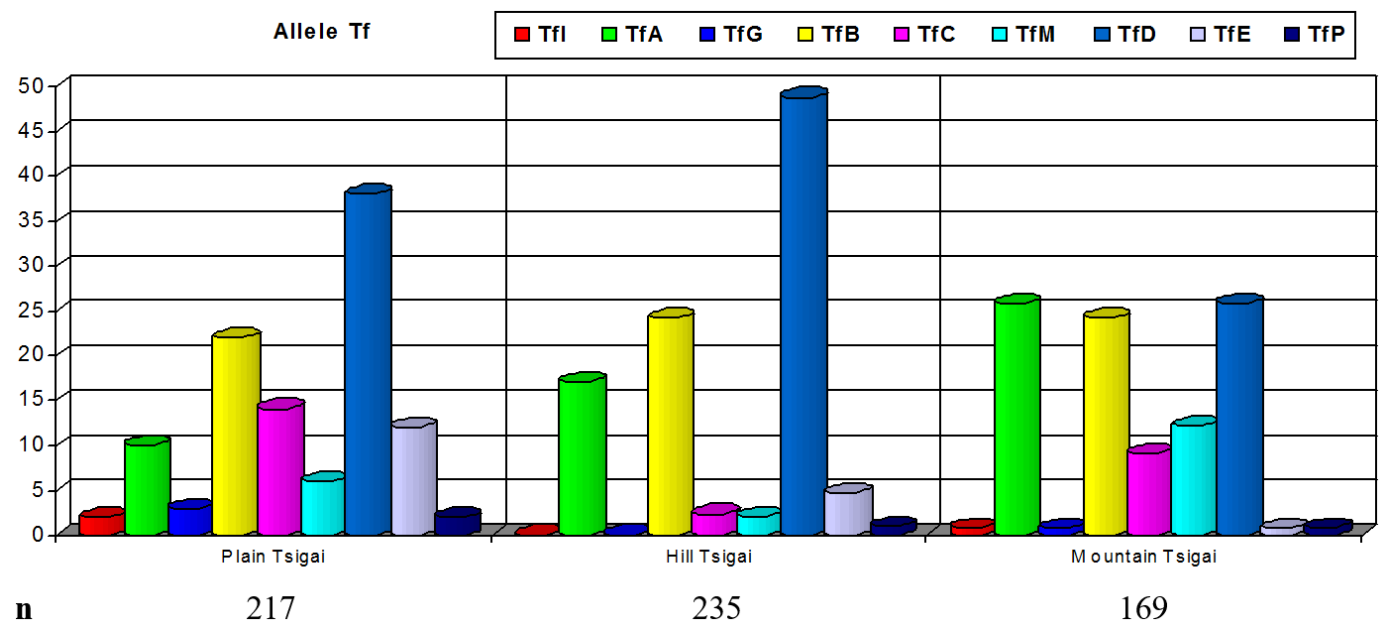

Fig. 2. Allelic structure at the Tf locus in different Tsigai ecotypes

than the $\mathrm{Hb}^{\mathrm{B}}$ allele $(37.50 \%)$. In the mountain ecotype (Calimani-Gurghiu Massif), the $\mathrm{Hb}^{\mathrm{A}}$ allele reaches the highest level of frequency $(84.86 \%)$, the $\mathrm{Hb}^{\mathrm{B}}$ allele having the weakest spread (Fig. 1).

\section{Allelic structures at the determinant locus of transferring}

Three Tsigai ecotypes were typified at the determinant locus of transferrin: the plain ecotype (Rusetu), the hill ecotope (Secuieni) and the mountain ecotype (Moroieni). All nine transferrin alleles are present in the Moroieni Tsigai while in the Secuieni Tsigai there are not the $\mathrm{Tf}^{\mathrm{I}}$ and $\mathrm{Tf}^{\mathrm{C}}$ alleles. In the Moroieni ecotype, the allele panel is mostly constituted by the $\mathrm{Tf}^{\mathrm{A}}, \mathrm{Tf}^{\mathrm{B}}$ and $\mathrm{Tf}^{\mathrm{D}}$ alleles (each nearly 25\%), the other alleles occupying a narrow or sometimes sporadic space such as the $\mathrm{Tf}^{\mathrm{1}}, \mathrm{Tf}^{\mathrm{G}}, \mathrm{Tf}^{\mathrm{E}}$ and $\mathrm{Tf}^{\mathrm{P}}$ alleles (less than $1 \%$ ). In the Secuieni ecotype, almost half of the population individuals possess the $\mathrm{Tf}^{\mathrm{D}}$ allele and a quarter of them have the $\mathrm{Tf}^{\mathrm{B}}$ allele. Also, the $\mathrm{Tf}^{\mathrm{A}}$ allele also records an important frequency (17\%). The other four alleles have a very low spread (between 1\% and $2.5 \%$ ). In such a situation it is clear that more transferrin genotypes will be expressed in the Moroieni Tsigai than in the Secuieni Tsigai and the genotypic configurations will be different in the two ecotypes. Although, the plain Tsigai (Rusetu) as nine alleles as the mountain Tsigai, its allelic incidences are relatively similar to those of hill Tsigai; in plain Tsigai the $\mathrm{Tf}^{\mathrm{A}}$ and $\mathrm{Tf}^{\mathrm{D}}$ alleles are less frequent and the $\mathrm{Tf}^{\mathrm{C}}$ and $\mathrm{Tf}^{\mathrm{E}}$ alleles are more spread than in hill Tsigai; at the same time, the allele dispersion is more uniform in plain Tsigai, the ratios among $\mathrm{Tf}$ alleles being slightly more balanced than in the hill ecotype (Fig. 2).

\subsection{Parameters of informational statistics Biological relationships}

Within the haemoglobin system, between the plain and the hill Tsigai, on the one hand, and the sub-mountain and the mountain Tsigai, on the other hand, the genetic distances are very large. The coefficients of informational correlation between the ecotypes from the lowland regions (plain and hill Tisgai) on the one hand are of medium level with sub-mountain Tisgai and have very low values with mountain Tsigai on the other hand. The plain Tsigai is genetically more distant from the sub-mountain Tsigai and especially from the mountain Tsigai compared to the hill Tsigai. There is a very high, almost absolute, genetic similarity between the plain Tsigai and the hill Tsigai, as well as between the pre-mountain Tsigai and the mountain Tsigai, but it is slightly lower than the previous interrelation. The informationalstatistical characteristics are concordant with allelic distributions. In the plain and hill ecotypes the $\mathrm{Hb}^{\mathrm{B}}$ allele is clearly predominant, while in the sub-mountain ecotypes and especially in the mountain ones the allele $\mathrm{Hb}^{\mathrm{A}}$ records high frequencies, but its $\mathrm{Hb}^{\mathrm{B}}$ codominant is moderately met in populations, too (Tab. 1, Fig. 3).

Within the transferrin system, the informational correlation coefficients achieved at the locus Tf among the three analyzed ecotypes record high values. The closest relationshiphip is established between the plain Tsigai and the hill 
Tab. 1. Genetic distances (D) and informational correlation coefficients $\left(R_{x, y}\right)$ among the Tsigai ecotypes, in terms of structure at the determinant haemoglobin locus

\begin{tabular}{ccccc}
\hline Ecotype & Plain Tsigai & Hill Tsigai & Submountain Tsigai & Mountain Tsigai \\
\hline Plain Tsigai & & 0.0004 & 0.5648 & 1.4337 \\
\hline Hill Tsigai & 0.9996 & 0.5249 & 1.3245 \\
\hline Submountain Tsigai & 0.5684 & 0.5916 & 0.0677 \\
\hline Mountain Tsigai & 0.2384 & 0.2659 & 0.9345 \\
\hline \multicolumn{5}{c}{$\mathrm{R}_{\mathrm{x}, \mathrm{y}}$} \\
\hline
\end{tabular}



PI.Tig - Plain Tsigai; HI.Tig - Hill Tsigai; Sm.Tig - Submountain Tsigai; Mt.Tig - Mountain Tsigai

Fig. 3. Informational correlation coefficients $\left(\boldsymbol{R}_{x, y}\right)$ among the Tsigai ecotypes, in terms of structure at the determinant haemoglobin locus

Tab. 2. Genetic distances (D) and informational correlation coefficients $\left(\mathrm{R}_{\mathrm{x}, \mathrm{y}}\right)$ among the Tsigai ecotypes, in terms of structure at the determinant transferrin locus

\begin{tabular}{cccc}
\hline Ecotype & Plain Tsigai (Rusetu) & Hill Tsigai (Secuieni) & $\begin{array}{c}\text { Mountain Tsigai } \\
\text { (Moroieni) }\end{array}$ \\
\hline Plain Tsigai Rusetu) & & 0.0956 & 0.1203 \\
\hline Hill Tsigai (Secuieni) & 0.9088 & 0.1295 \\
\hline Mountain Tsigai (Moroieni) & 0.886 & 0.8785 & \\
\hline & $\mathrm{R}_{\mathrm{x}, \mathrm{y}}$ \\
\hline
\end{tabular}

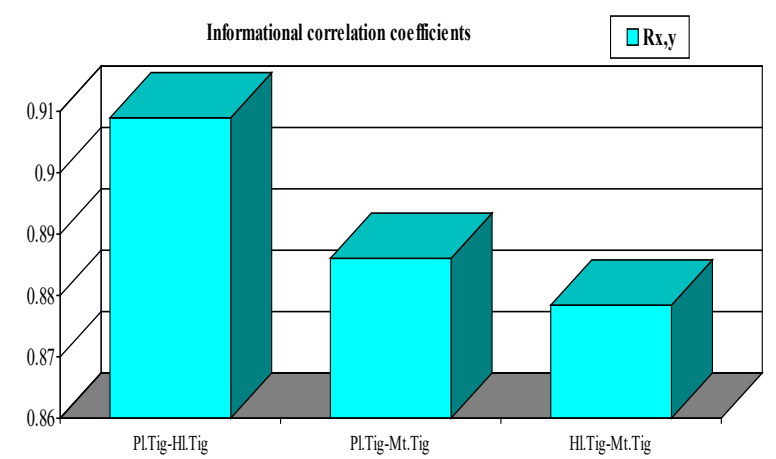

Pl.Tig - Plain Tsigai (Rusetu); Hl.Tig-- Hill Tsigai (Secuieni); Mt.Tig- Mountain Tsigai (Moroieni)

Fig. 4. Informational correlation coefficients $\left(\boldsymbol{R}_{\boldsymbol{x}, \boldsymbol{y}}\right)$ among the Tsigai ecotypes, in terms of structure at the determinant transferrin locus 


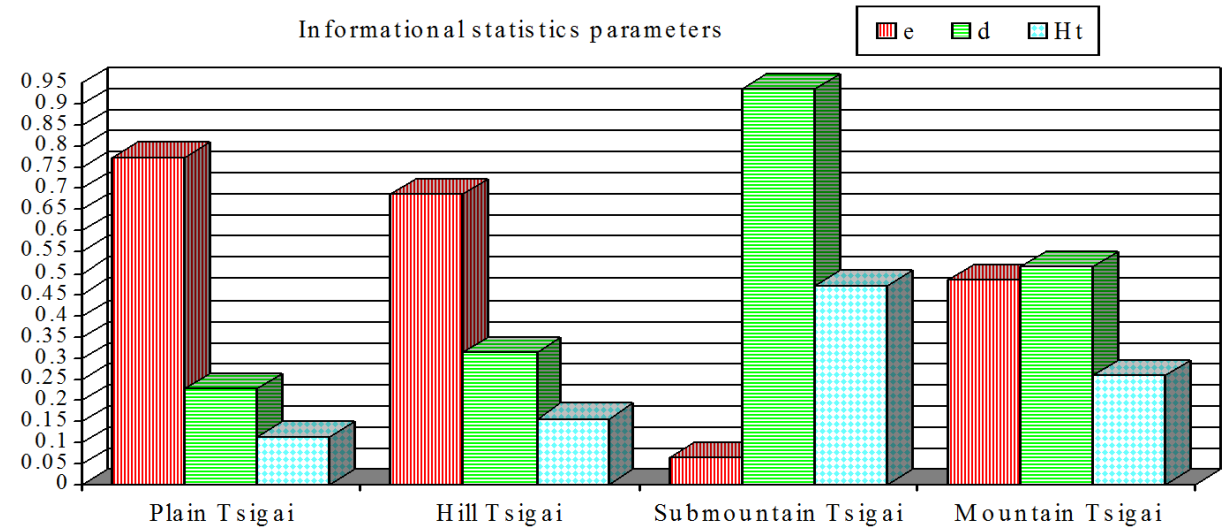

Fig. 5. Coefficients of informational energy $(\boldsymbol{e})$ genetic diversity $(\boldsymbol{d})$ and heterozygosity $(\boldsymbol{H t})$ at the $\mathrm{Hb}$ locus in Tsigai ecotypes from Romania

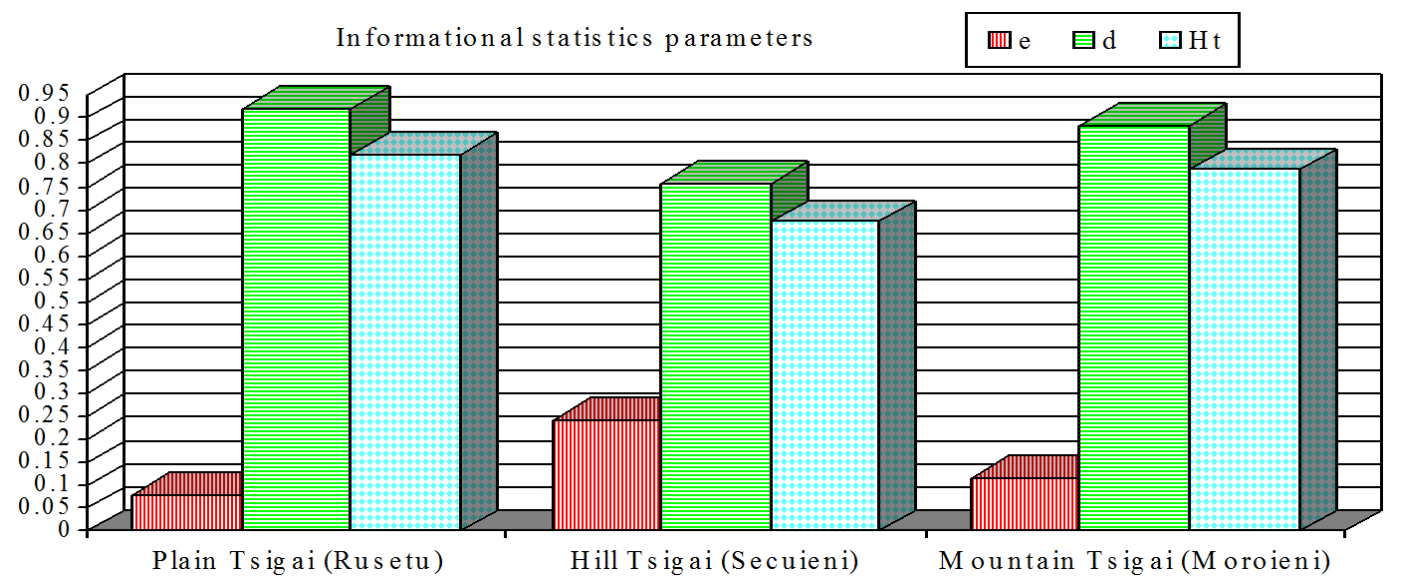

Fig. 6. Coefficients of informational energy $(\boldsymbol{e})$ genetic diversity $(\boldsymbol{d})$ and heterozygosity $(\boldsymbol{H t})$ at the Tf locus in Tsigai ecotypes from Romania

Tsigai. The plain Tsigai is slightly more genetically distant than the mountain Tsigai; almost at the same level there is the relationshiphip between the hill Tsigai and the mountain Tsigai (Tab. 2, Fig. 4).

\section{Genetic diversity}

The distribution way of alleles within the panels of the genetic-biochemical systems represent the determinant element of the genetic diversity status of the ecotypes. In the haemoglobin system, the richest diversity is found in the submountain Tsigai ecotype (Ciuc Depression). This fact happens because the two haemoglobin alleles are spread more evenly than in the other ecotypes. In the ecotypes from low areas, the very high frequency of the $\mathrm{Hb}^{\mathrm{B}}$ allele in the detriment of its $\mathrm{Hb}^{\mathrm{A}}$ codominant leads to the development of a large informational energy that translates through a moderate genetic diversity. According to the allelic panel, the haemoglobin diversity of the hill ecotype is higher than of the plain ecotype. In the mountain ecotype, the $\mathrm{Hb}^{\mathrm{A}}$ allele dominates the haemoglobin table, but the differences between the frequencies of the two alleles are lower than in the ecotypes from the lower relief areas. In the mountain ecotype, the $\mathrm{Hb}^{\mathrm{A}}$ allele dominates the haemoglobin panel, but the differences between the frequencies of the two alleles are lower than in the ecotypes from the lower relief areas. Therefore, although the information energy is relatively large, the genetic diversity reaches a medium level, but it is incomparably lower than that of the submountain ecotype. The sub-mountain Tsigai is the only ecotype in which the informational energy is approximately equal to the genetic diversity at the Hb locus (Fig. 5).

Within the transferrin system, in all ecotypes, the genetic diversity is developed due to the emphasized polymorphism at this 


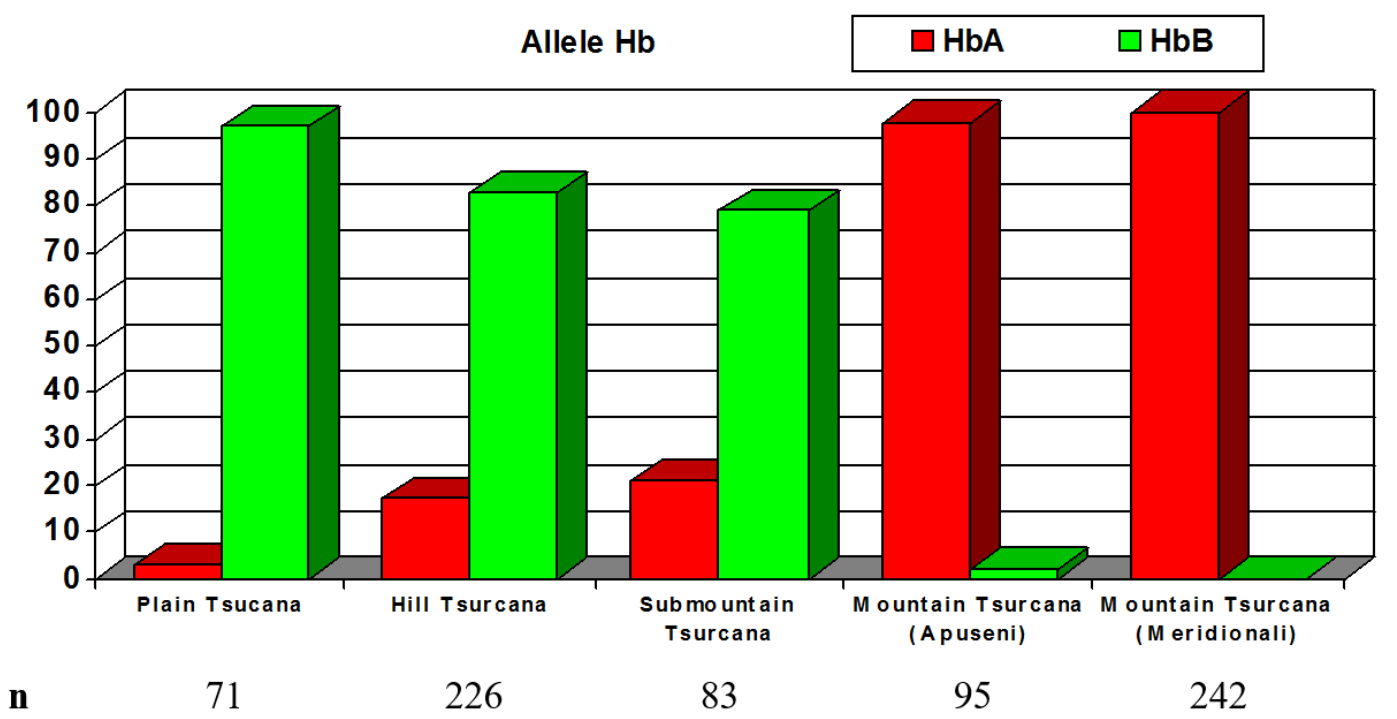

Fig. 7. Allelic structure at the Hb locus in different Tsurcana ecotypes

locus materialized by the presence of the nine transferrin alleles (Fig. 6). In the ecotypes from very low regions (plain), as well as in the ones from very high ones (mountain), the genetic diversity achieves very high levels. This situation is explained by the fact that in both ecotypes there is the same number of transferrin alleles (nine) and a better combinatorial capacity of these in transferrin genotypes. Due to the fact that in the plain ecotype the transferin alleles are more evenly distributed, the genetic diversity is 0.04 more developed than in the mountain ecotype. Compared to these, in the hilly ecotype the transferrin diversity is lower, however achieving an important enough value of the coefficient. One fact that determines this transferrin diversity level of is that there are only seven transferrin alleles in this ecotip, the $\mathrm{Tf}^{1}$ and $\mathrm{Tf}^{\mathrm{G}}$ alleles missing from this panel.

From a systemic point of view, the transferrin diversity is much higher than the haemoglobin diversity in most of the Tsigai ecotypes.

\section{Particularities of biodiversity in the Tsurcana ecotypes}

As with Tsigai, in the Tsurcana too, the biodiversity aspects of its ecotypes were based on the allelic frequencies of the haemoglobin and transferin systems, depending on the relief forms in which they live: the Tsurcana plain (an isolated nucleus in Dobrudja), the hill Tsurcana (Popăuţi), sub-mountain Tsurcana (Caransebeş) and mountain Tsurcana from two massifs: Apuseni
Mountains (West Carpathians) and Meridionali Mountains (South Carpathians).

\subsection{Allelic structures of biochemical-genetic systems}

Allelic structures at the determinant locus of haemoglobin

The Tsurcana breed from Romania is characterized by large differences concerning the spread of haemoglobin alleles within populations of different areas. In the plain sheep (some isolated populations in Dobrudja left as a result of transhumance) there is almost only the $\mathrm{Hb}^{\mathrm{B}}$ allele, the $\mathrm{Hb}^{\mathrm{A}}$ allele being only sporadically found. It is a structure similar to that found in Tsurcana of the Hungarian puszta. For Turcana from the Meridionali Mountains the preponderance of the $\mathrm{Hb}^{\mathrm{A}}$ allele (98\%) is specific, while in Tsurcana from the hilly area of Moldavia, the $\mathrm{Hb}^{\mathrm{B}}$ allele dominates the haemoglobin pool (79\%), and the $\mathrm{Hb}^{\mathrm{A}}$ allele has a relatively low spread; moreover, in some populations (in the South Carpathians), the only genotype present is the homozygous one $\mathrm{Hb}^{\mathrm{A}} \mathrm{Hb}^{\mathrm{A}}$, the $\mathrm{Hb}^{\mathrm{B}}$ allele being completely eliminated. As for the hemoglobin table in sub-mountain Tsurcana the configuration of the allelic distributions is more similar to that of the plain and hill ecotypes than to those from mountain areas (Fig.7).

Allelic structures at the determinant locus of transferrin

Of the two Tsurcana ecotypes that were typified at the Tf locus, Caransebes Turcana is 


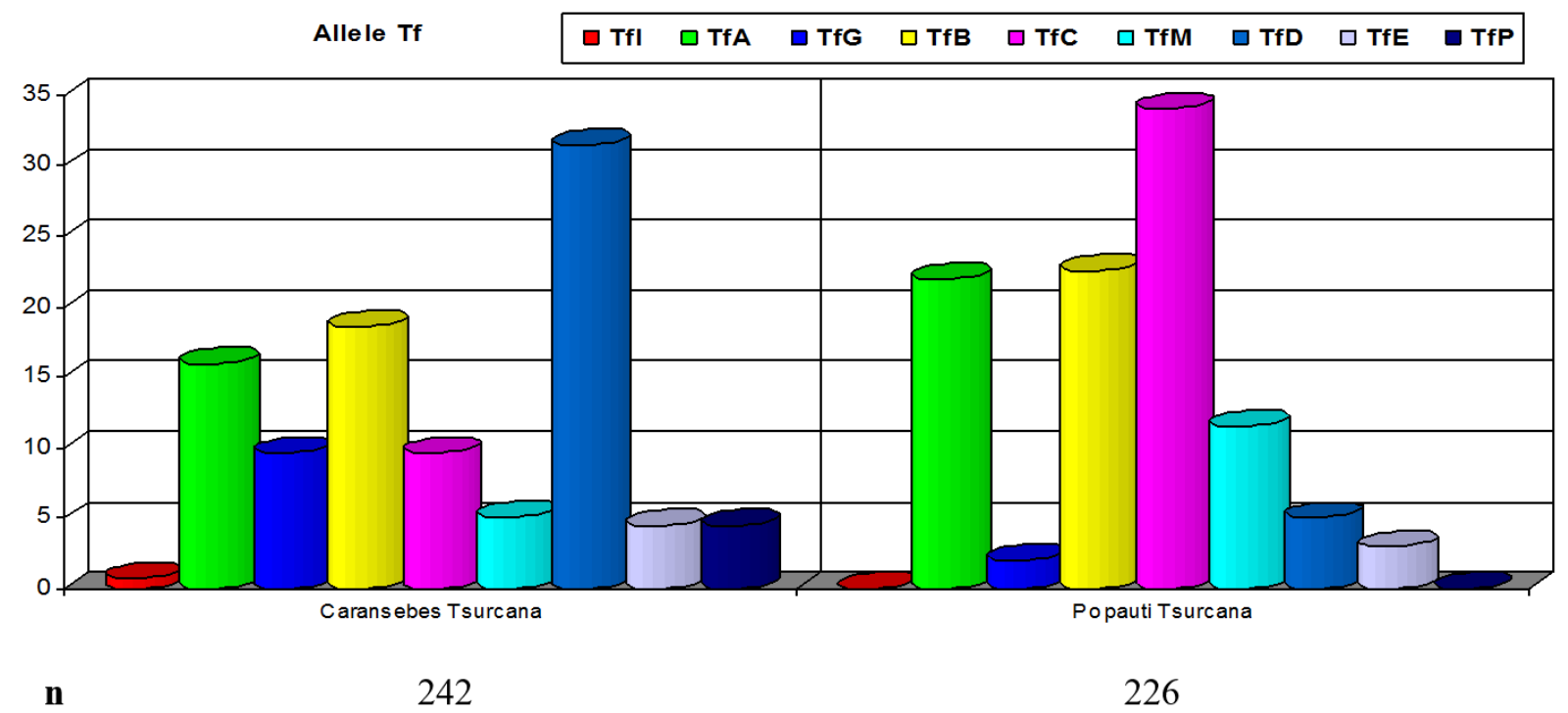

Fig. 8. Allelic structure at the Tf locus in different Tsurcana ecotypes

Tab. 3. Genetic distances (D) and informational correlation coefficients $\left(\mathrm{R}_{x, y}\right)$ among the Tsurcana ecotypes, in terms of structure at the determinant haemoglobin locus

\begin{tabular}{|c|c|c|c|c|c|}
\hline Ecotype & $\begin{array}{l}\text { Plain Tsurcana } \\
\text { (Dobrudja) }\end{array}$ & $\begin{array}{l}\text { Hill Tsurcana } \\
\text { (Popauţi) }\end{array}$ & $\begin{array}{c}\text { Submountain } \\
\text { Tsurcana } \\
\text { (Caransebes) }\end{array}$ & $\begin{array}{c}\text { Mountain } \\
\text { Tsurcana } \\
\text { (Apuseni) }\end{array}$ & $\begin{array}{c}\text { Mountain } \\
\text { Tsurcana } \\
\text { (Meridionali) }\end{array}$ \\
\hline $\begin{array}{l}\text { Plain Tsurcana } \\
\text { (Dobrudja) }\end{array}$ & & 0.0147 & 0.0264 & 2.9700 & 3.4766 \\
\hline Hill Tsurcana (Popauţi) & 0.9854 & & 0.0017 & 1.5114 & 1.6062 \\
\hline $\begin{array}{l}\text { Submountain Tsurcana } \\
\text { (Caransebes) }\end{array}$ & 0.9739 & 0.9983 & & 1.2853 & 1.3591 \\
\hline $\begin{array}{l}\text { Mountain Tsurcana } \\
\text { (Apuseni) }\end{array}$ & 0.0513 & 0.2206 & 0.2766 & & 0.0002 \\
\hline $\begin{array}{l}\text { Mountain Tsurcana } \\
\text { (Meridionali) }\end{array}$ & 0.0309 & 0.2006 & 0.2569 & 0.9998 & \\
\hline
\end{tabular}

more polimorphic than Moldova Tsurcana. In the Caransebes ecotype all nine alleles are found and only seven are present in the Popauti ecotype, lacking the $\mathrm{Tf}^{1}$ and $\mathrm{Tf}^{\mathrm{P}}$ marginal alleles. Also, the two ecotypes are also differentiated in terms of allelic distributions. In the Caransebes ecotype, the highest frequency is made by the $\mathrm{Tf}^{\mathrm{D}}$ allele (31.4\%), followed at a considerable distance by the $\mathrm{Tf}^{\mathrm{A}}$ and $\mathrm{Tf}^{\mathrm{B}}$ alleles $(16 \%$, respectively $18 \%)$, while in the ecotype from Moldova the $\mathrm{Tf}^{\mathrm{C}}$ allele (34\%) is most frequent met and the following alleles, $\mathrm{Tf}^{\mathrm{A}}$ and $\mathrm{Tf}^{\mathrm{B}}$ (each approximately 22\%), have frequencies closer to that of the $\mathrm{Tf}^{\mathrm{C}}$ allele. Besides these, only the $\mathrm{Tf}^{\mathrm{C}}$ allele $(9.6 \%)$ in the Caransebes ecotype and the $\mathrm{Tf}^{\mathrm{M}}$ allele $(11.5 \%)$ in the Moldavian ecotype achieves more substantial frequencies, the other alleles having a very low contribution to the completion of the allelic table in both ecotypes (between $0.5 \%$ and 5\%) (Fig. 8).

\subsection{Parameters of informational statistics Biological relationships}

At the determinant haemoglobin locus there is a great genetic similarity among the Tsurcana ecotypes bred in the plain, hill and submountain areas. The similarity is more obvious between the hill and sub-mountain Tsurcana than between these two ecotypes and the plain Tsurcana. All these three ecotypes from regions with lower altitudes differ fundamentally from 


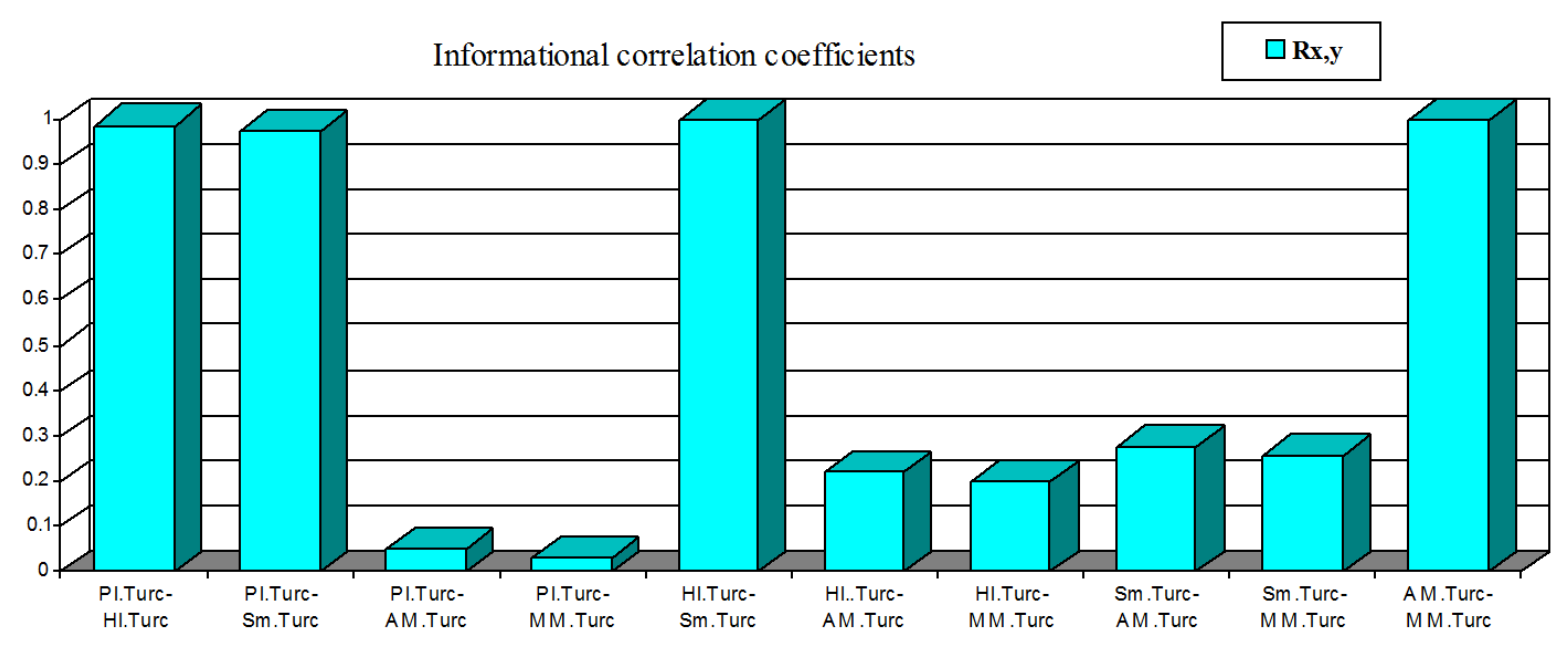

PI.Turc - Plain Tsurcana; H.Turc - Hill Tsurcana; Sm.Turc- Submountain Tsurcana; Mt.Turc. - Mountain Tsurcana (Apuseni); MM.Turc - Mountain Tsurcana (Meridionali)

Fig. 9. Informational correlation coefficients $\left(\mathbf{R}_{x, y}\right)$ among the Tsurcana ecotypes, in terms of structure at the determinant haemoglobin locus

Tab. 4. Genetic distances (D) and informational correlation coefficients $\left(\mathrm{R}_{x, y}\right)$ among the Tsurcana ecotypes, in terms of structure at the determinant transferrin locus

\begin{tabular}{ccc}
\hline Ecotype & $\begin{array}{c}\text { Caransebes } \\
\text { Tsurcana }\end{array}$ & $\begin{array}{c}\text { Popauti } \\
\text { Tsurcana }\end{array}$ \\
\hline $\begin{array}{c}\text { Caransebes } \\
\text { Tsurcana }\end{array}$ & 0.4281 \\
\hline $\begin{array}{c}\text { Popauti } \\
\text { Tsurcana }\end{array}$ & 0.6517 & \\
\hline & $\mathrm{R}_{\mathrm{x}, \mathrm{y}}$ & \\
\hline
\end{tabular}

the informational-statistical point of view of the Tsurcana ecotypes from the mountainous regions, the genetic distances between the two of ecotype groups being very large. The Tusrcana ecotypes from plain, hill and sub-mountainous areas are slightly more distant to the mountainous Tsurcana from the Southern Carpathians than to the one from the Apuseni Mountains. Between the two mountain ecotypes, the informational correlation is very strong having an almost absolute value. As with Tsigai, in large part, the informationalstatistical characteristics of the Tsurcana ecotypes are concordant with the distributions of the two haemoglobin alleles of each ecotype. In the ecotypes from plain, hilly and sub-mountain areas

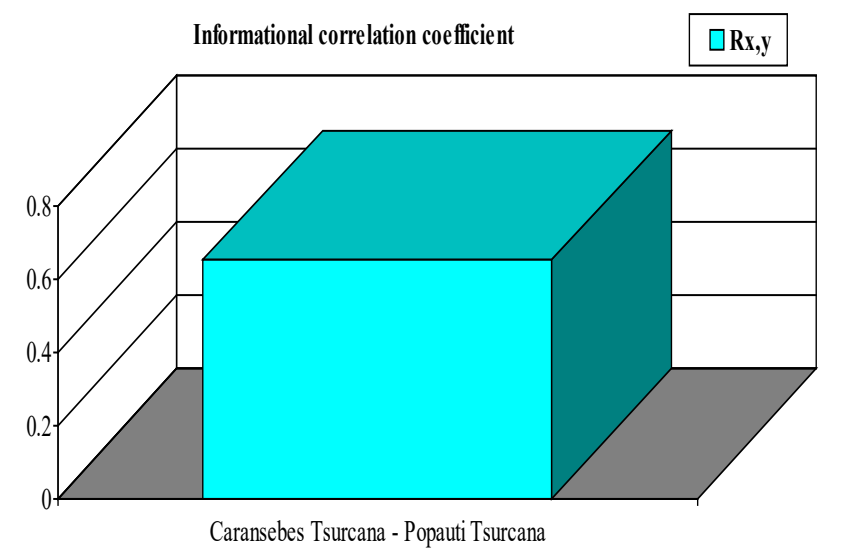

Fig. 10. Informational correlation coefficients $\left(\boldsymbol{R}_{x, y}\right)$ among the Tsurcana ecotypes, in terms of structure at the determinant transferrin locus

the $\mathrm{Hb}^{\mathrm{B}}$ allele is clearly predominant, while in the ecotypes from the high mountainous areas only the $\mathrm{Hb}^{\mathrm{A}}$ allele is present (in the Meridionali Mountains) or occupies almost all the haemoglobin panel, the $\mathrm{Hb}^{\mathrm{B}}$ allele being sporadically spread (in the Apuseni Mountains) (Tab. 3, Fig. 9).

Within the transferin system the comparison was made between the Popauti Tsurcana and Caransebeş Tsurcana having experimental data only in these two ecotypes. Between these two ecotypes the genetic distance is quite significant and the informational correlation coefficient records a value situated slightly above the medium level (Tab. 4, Fig. 10). 




Fig. 11. Coefficients of informational energy $(\boldsymbol{e})$ genetic diversity $(\boldsymbol{d})$ and heterozygosity $(\boldsymbol{H t})$ at the Hb locus in Tsurcana ecotypes from Romania

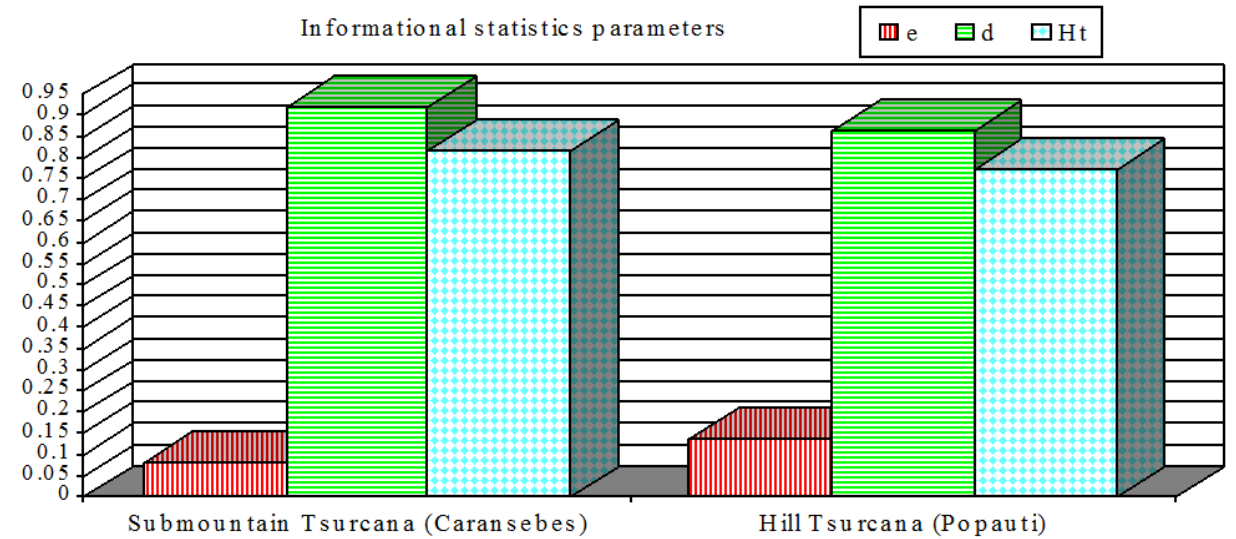

Fig. 12. Genetic distances (D) and informational correlation coefficients $\left(R_{x, y}\right)$ among the Tsurcana ecotypes, in terms of structure at the determinant transferrin locus

\section{Genetic diversity}

The distributional characteristics of the two haemoglobin alleles determine the medium or very low levels of genetic diversity at this locus in both ecotypes (Fig. 11). Both in the plain ecotype and in the mountain ecotype from Apuseni the informational energy amount is so great that the haemoglobin diversity is relatively low (in the plain Tsurcana) or extremely low or almost inexistent (in theTsurcana from West Carpathians); moreover, in the Meridionali ecotype the informational energy is maximal and the genetic diversity is null. In the ecotypes from hilly and sub-mountain areas, due to a more balanced distribution between the two types of alleles, the genetic diversity is developed having levels above 0.5, especially in submountain Tsurcana. However, in both situations, the informational energy reaches lower values than the genetic diversity coefficients.

Within the transferrin system, in both ecotypes analyzed, we find extremely high genetic diversity as a result of the balanced ratios of the transferrin allele frequencies. The distribution uniformity of the transferin alleles is more pronounced in the Caransebes ecotype than in the Popauti one, fact reflected in the values of their genetic diversity coefficients .

Also, in the Tsurcana ecotypes, the transferrin diversity is more developed than the haemoglobin diversity. 
The intensity of biological relationships between ecotypes of the Tsigai and Tsurcana breeds, as well as the characteristics of the genetic diversity within them reflect mainly the particularities of the environmental conditions and, in the alternative, the specificity of the selection criteria and technological factors used for the improvement and breeding process of these breed subdivisions formed according to the relief forms of their habitats. The characteristics of the informational-statistical edifice based on the genetic variants of haemoglobin and transferrin resize the biological relationshiphips among the ecotypes within each breed and quantify with greater accuracy their genetic patrimony at the level of the two polymorphic loci. Compared to the genetic distance, the informational correlation provides more flexibility to the investigational methodology, it is more expressive and has the advantage to benefit of graphic representation.

In general, it comes out a closer relationshiphip among the Tsigai ecotypes than among those of the Tsurcana breed in both biochemical-genetic systems. In the same context, in the ecotypes of both breeds the transferrin diversity achieves higher levels than the haemoglobin diversity. Also, considering the two biochemical-genetic systems, it can be noticed that the Tsigai ecotypes achieve higher levels of genetic diversity than the Tsurcana ecotypes.

The heterozigosity is a first indicator of genetic diversity and an essential factor in increasing this biodiversity. In absolute value, the genetic diversity is higher than the heterozigogosity. But there is a direct linearity relation between the genetic diversity level and the heterozygosity degree. The ratio between these two sizes depends on the allele number of polymorphic loci. Thus, in all ecotypes of the Tsigai and Tsurcan breeds the haemoglobin heterozygosity degree differs from the transferrin heterozygosity degree with reference to the genetic diversity levels at these two loci. If the haemoglobin diversity level is twice as high (100\%) as haemoglobin heterozygosity degree, the transferinic diversity level is only $12 \%$ higher than the haemoglobin heterozygosity degree. And this aspect should be interpreted in the context in which the transferrin diversity is much richer than the haemoglobin diversity (Figs. $5,6,11,12)$.
These informational statistics analyzes that use genetic markers in the computational algorithm are important tools for evaluating the evolution directions of the Tsigai and Tsurcana ecotypes from Romania and for the substantiation of the preservation and improvement programs for their genetic patrimony.

\section{CONCLUSIONS}

The genetic differentiation / similarity degree and the genetic diversity level were quantified in the ecotypes belonging to Tsigai and Tsurcana breeds from Romania by means of informational statistics concepts.

Differences were found among the different ecotypes of the Tsigai and Tsurcana breeds regarding both the biological relationshiphips among them and in terms of genetic diversity, differentiations due to the allele configurations in the haemoglobin and transferrin systems whose fixation is determined by the ecological factors in the existence areas of the ecotypes.

In general, there is a stratification and tiebreaker of the Tsigai and Tsurcana ecotypes from the genetic structure point of view from the $\mathrm{Hb}$ and $\mathrm{Tf}$ locus level, as well as the values of informational-statistical parameters defining the biodiversity in relation to the relief forms (plain, hill, sub-mountain and mountain) of the areas where the ecotypes live.

From a systemic point of view, the biological relationshiphips are tighter among ecotypes and genetic diversity has higher levels within them in the Tsigai breed compared to the Tsurcana breed.

In the ecotypes of both breeds the transferrin diversity is higher than the haemoglobin diversity, and the difference between the diversity and heterozygosity from the $\mathrm{Hb}$ locus is much larger than the difference between the diversity and heterozygosity from the Tf locus.

Determination of informational statistics parameters on genetic basis is useful in the conservation and improvement process of the genetic patrimony of Tsigai and Tsurcana ecotypes.

\section{REFERENCES}

1. Grosu H, Drăgănescu C (2003). Ameliorarea animalelor, Ed Coral Sanivet, București.

2. Gáspárdy A (2011). Ecotypes - breed variants adapted to different environments, in example of Tsigai haemoglobin genotypes. 5th European Seminar on Agrobiodiversity 22- 
25 of September 2011, Dimitrovgrad, Serbia. Combined Annual Meeting of SAVE and of DAGENE.

3. Hrincă Gh, Vicovan G (2010). Comparative analysis of the haemoglobin system in the Romanian sheep breeds. Ann Rom Soc Cell Biol, XV (2), Edit Risoprint, ClujNapoca:32-40.

4. Hrincă Gh, Vicovan G (2011). Comparative analysis of the transferrin system in the Romanian sheep breeds. Ann Rom Soc Cell Biol, XVI (1), Edit Risoprint, ClujNapoca:16-31.

5. Hrincă Gh (2015). Modern methodology for quantifying the biodiversity in ovine species based on genetic markers using the concepts of informational statistics. Proc Rom Acad, Series B: Chemistry, Life Sciences and Geoscience, 17(3): 273-289.

6. Ozdemir M, Bilgin OC, Esenbuga N (2011). Determination of genetic distance between Turkish sheep breeds with various methods using some blood protein loci. J Anim \& Plant Sci, 21(3):459-464.

7. Paraschivescu MTh, Bogdan AT, Paraschivescu M, Tobă GF, Stan S (2009). Biodiversity in farm animals: sources, using, conservation. Sci Pap Agr Sci Vet Med Univ Bucharest, Series D, LII, Anim Sci:89-95.

8. Sargent J, van der Bank FH, Kotze A (1999). Genetic variation in blood proteins within and between 19 sheep breeds from southern Africa. S Afr Anim Sci 29 (3):245257.

9. Scher B, Galal S, Hoffmann I (Editors) (2012). Animal Genetic Resources. Food and Agriculture Organization of the United Nations.

10. Zanoti Casati M, Gandini GC, Leone P (1990). Genetic variation and distances of five Italian native breeds. Anim Genet, 21:87-92. 